\title{
Supplemental Choline for Prevention and Alleviation of Fatty Liver in Dairy Cattle
}

\author{
R. F. Cooke, N. Silva del Río, D. Z. Caraviello, S. J. Bertics, M. H. Ramos, and R. R. Grummer ${ }^{1}$ \\ Department of Dairy Science, University of Wisconsin, Madison 53706
}

\begin{abstract}
Two experiments were conducted to evaluate if supplementing rumen-protected choline (RPC; Reashure, Balchem Encapsulates, Slate Hill, NY) could prevent or alleviate fatty liver in dairy cattle. The first experiment evaluated the effect of supplementing RPC on hepatic triacylglycerol (TAG) accumulation during fatty liver induction. Twenty-four dry cows between 45 to $60 \mathrm{~d}$ prepartum were paired by body weight (BW) and body condition score (BCS) and randomly assigned to control or supplementation with $15 \mathrm{~g}$ of choline as RPC/d. From d 0 to 6 , before treatment application, all cows were fed $1.4 \mathrm{~kg} / \mathrm{d}$ of concentrate and forage ad libitum. Samples of blood and liver, obtained during the pretreatment period, were used for covariate adjustment of blood metabolites and liver composition data. During fatty liver induction (d 7 to 17), cows were fed $1.4 \mathrm{~kg} / \mathrm{d}$ of concentrate with or without supplementation with RPC, and forage intake was restricted, so cows consumed $30 \%$ of the total energy requirements for pregnancy and maintenance. Supplementation with RPC during fatty liver induction did not affect plasma glucose and plasma $\beta$-hydroxybutyrate (BHBA) concentration but did decrease plasma nonesterified fatty acid (NEFA; 703 vs. $562 \mu \mathrm{Eq} / \mathrm{L}, \mathrm{SE}=40)$ and liver TAG accumulation (16.7 vs. $9.3 \mu \mathrm{g} / \mu \mathrm{g}$ of DNA, $\mathrm{SE}=2.0$ ). In the second experiment, we evaluated the effect of supplementing RPC on the clearance of liver TAG when cows were fed ad libitum after the induction of fatty liver by feed restriction. Twenty-eight cows between 45 and $60 \mathrm{~d}$ prepartum were paired according to BCS and BW and assigned to treatments. Fatty liver was induced by feeding $1.4 \mathrm{~kg} /$ $\mathrm{d}$ of concentrate (without RPC) and restricting forage intake, so cows consumed $30 \%$ of maintenance and pregnancy energy requirements for $10 \mathrm{~d}$. From d 11 to 16 , after feed restriction, cows were fed forage ad libitum and $1.4 \mathrm{~kg} / \mathrm{d}$ of concentrate with or without RPC. Treatments were not applied during fatty liver induc-
\end{abstract}

Received January 18, 2006.

Accepted January 9, 2007.

${ }^{1}$ Corresponding author: rgrummer@wisc.edu tion; however, following feed restriction, liver for cows assigned to control and RPC treatments contained 6.8 and $12.7 \mu \mathrm{g}$ of TAG/ $\mu \mathrm{g}$ of DNA, respectively. Measurements obtained before treatment served as covariates for statistical analysis. During the depletion phase, plasma glucose, BHBA, and NEFA were not affected by treatment. Liver TAG, expressed as covariate adjusted means, was 6.0 and $4.9 \mu \mathrm{g} / \mu \mathrm{g}$ of DNA (SE $=0.4$ ) on d 13 , and 5.0 and $1.5 \mu \mathrm{g} / \mu \mathrm{g}$ of DNA $(\mathrm{SE}=0.9)$ on d 16 for control and RPC, respectively. Rumen-protected choline can prevent and possibly alleviate fatty liver induced by feed restriction.

Key words: dairy cattle, choline supplementation, feed restriction, fatty liver

\section{INTRODUCTION}

Fatty liver is a metabolic disorder that can affect up to $50 \%$ of high-producing dairy cows during the transition period, potentially compromising health, production, and reproduction (Jorritsma et al., 2000). Fatty liver is associated with elevated NEFA resulting from depressed feed intake and endocrine changes that occur in the periparturient period (Grummer, 1995). The NEFA concentration at which triacylglycerol (TAG) begins to accumulate in liver is not well established, but it is known that the hepatic uptake of NEFA is directly associated with their concentration in blood (Bell, 1980).

Accumulation of TAG in the liver has been shown to decrease the rate of hepatic ureagenesis, gluconeogenesis, hormonal clearance, and responsiveness (Strang et al., 1998a,b). Therefore, prevention of fatty liver may be necessary to maintain optimal hepatic function during the periparturient period. Fatty liver incidence could be reduced either by suppressing fatty acid mobilization from adipose tissue, or by enhancing the TAG export as lipoproteins from the liver or by both mechanisms. However, in ruminants the modest hepatic export of TAG as very low density lipoprotein (VLDL; Kleppe et al., 1988), and the lack of practical methods to enhance VLDL export precludes an increase in TAG export as an option for reducing fatty liver. 
When rats were fed choline-deficient diets, liver TAG accumulation increased significantly (Griffith, 1941). Active synthesis of phosphatidylcholine (PC) derived from choline is essential for the hepatic synthesis and secretion of VLDL (Yao and Vance, 1988). There are 2 pathways for PC synthesis: condensation of choline with diacylglycerol, and methylation of phosphatidylethanolamine with $S$-adenosylmethionine as methyl donor. Because of the extensive choline degradation by the rumen microbial population (Atkins et al., 1988; Sharma and Erdman, 1989), it has been speculated that ruminants may be choline deficient and consequently, more susceptible to fatty liver (Erdman, 1992). It is our assumption that supplementing choline to ruminants would ensure an adequate choline supply and spare methyl donors such as methionine, thus enhancing PC synthesis and apolipoprotein assembly. However, the only effective way to increase choline flow to the intestine of ruminants is by feeding choline in a rumenprotected form (Atkins et al., 1988).

The objective of the present work was to determine the effects of rumen-protected choline (RPC) on liver TAG accumulation. Supplementation with RPC was evaluated in 2 different scenarios: during a period of negative energy balance when hepatic TAG was accumulating, and after a period of negative energy balance when positive energy balance was restored and TAG was being cleared by the liver.

\section{MATERIALS AND METHODS}

\section{Animals}

All animals were pregnant, nonlactating, multiparous Holstein cows. They were housed in individual tie stalls bedded with sawdust. The University of Wisconsin, College of Agricultural and Life Sciences, Animal Care and Use Committee approved all animal procedures.

\section{Experiment 1}

Experiment 1 was conducted to determine if RPC (Reashure, Balchem Encapsulates, Slate Hill, NY) reduces hepatic TAG accumulation during negative energy balance. Twenty-four cows between 45 and $60 \mathrm{~d}$ prepartum were paired by BW and BCS based on a 5point scale $(1=$ emaciated, $3=$ average, and $5=$ obese; Wildman et al., 1982), and randomly assigned to 1 of 2 treatments: 1) control, or 2) $15 \mathrm{~g}$ of choline as RPC per day ( $60 \mathrm{~g} / \mathrm{d}$ as Reashure). The animals were divided into 2 groups of 12 cows each (6 pairs per group) that went through the protocol $4 \mathrm{wk}$ apart. The duration of the experimental period was $17 \mathrm{~d}$. From $\mathrm{d} 0$ to 6 , cows were fed a standard diet based on a forage mix with
$50 \%$ alfalfa silage $(42 \% \mathrm{NDF}$ and $21 \% \mathrm{CP}$ on a DM basis) and $50 \%$ corn silage (38\% NDF and $9 \% \mathrm{CP}$ on a DM basis) fed ad libitum, and offered twice a day, at 0730 and $1500 \mathrm{~h}$. Nutrient composition of forage was determined on a 6500 NIR spectrophotometer (Foss in North America, Eden Prairie, MN) using equations of the NIRS Consortium (Lundberg et al., 2004). Vitamins and minerals were fed to meet requirements (NRC, 2001), mixed with $1.4 \mathrm{~kg}$ of corn-based concentrate. Vitamins represented $1.0 \%$ of the DM of the concentrate (3,304 IU/g of DM of vitamin A, 1,101 IU/g of DM of vitamin $\mathrm{D}$, and $55 \mathrm{IU} / \mathrm{g}$ of $\mathrm{DM}$ of vitamin $\mathrm{E}$ ) and minerals represented $0.6 \%$ of the DM of the concentrate $(0.55 \% \mathrm{Mn}, 0.55 \% \mathrm{Zn}, 0.35 \% \mathrm{Fe}, 0.14 \% \mathrm{Cu}, 0.008 \% \mathrm{I}$, $0.006 \%$ Se, and $0.002 \%$ Co).

On $d 7$, cows were restricted to $30 \%$ of the energy required for pregnancy and maintenance (NRC, 2001) by restricting the intake of a forage mix, based on equal proportions of alfalfa silage, corn silage, and wheat straw that was offered once a day in the morning in addition to the $1.4 \mathrm{~kg}$ of concentrate previously described. Wheat straw analysis indicated a CP content of 3.5\% (method 2001.11; AOAC, 2006) and 77\% NDF (Mertens, 1999).

During feed restriction, cows continued to receive vitamins and minerals in addition to the treatments $(0$ or $15 \mathrm{~g}$ of choline as RPC) via the concentrate mix administration. Blood was sampled from coccygeal vein or artery at 2 and $0 \mathrm{~h}$ before morning feeding, and at 2,4 , and $6 \mathrm{~h}$ after morning feeding on $\mathrm{d} 5$ and 16 . Liver samples were obtained via needle biopsy on d 6 and 17 . Blood and liver measurements obtained on d 5 and 6 served as covariate within each variable for statistical analysis.

\section{Experiment 2}

Experiment 2 was conducted to determine if RPC would alter the extent of TAG depletion from liver when cows were in positive energy balance following induction of fatty liver by feed restriction. Twenty-eight cows between 45 and $60 \mathrm{~d}$ prepartum were paired by BW and BCS, and randomly assigned to 1 of 2 treatments: 1) control, or 2) $15 \mathrm{~g}$ of choline as RPC per day. The animals were divided into 2 groups of 14 cows each (7 pairs per group) that went through the protocol $4 \mathrm{wk}$ apart. Before receiving treatments, cows were restricted to $30 \%$ of their energy requirements for pregnancy and maintenance for $10 \mathrm{~d}$, similarly to experiment 1 . On the last day of feed restriction (d 10), blood was sampled from the coccygeal vein or artery immediately before and $4 \mathrm{~h}$ after feeding. Additionally, a liver sample was obtained following the last blood sampling, and these measurements were used to covariately ad- 
just the data. From d 11 to 16 , cows were fed a standard diet, which consisted of free-choice forage mix (see experiment 1), $1.4 \mathrm{~kg} / \mathrm{d}$ of concentrate containing vitamins and mineral to meet requirements, and 0 or $15 \mathrm{~g}$ of choline as RPC/d. Cows were fed forage mix twice a day $(0730$ and $1500 \mathrm{~h})$, and the concentrate was offered 30 min before morning feeding. Dry matter intake was measured daily during this 6-d period. On $\mathrm{d} 13$ and 16, blood samples were collected immediately before and 4 $\mathrm{h}$ after morning feeding, and a liver sample was obtained after the last blood sampling.

\section{Blood and Liver Analysis}

Blood samples were collected in Vacutainer tubes containing potassium oxalate as anticoagulant and sodium fluoride as a glycolytic inhibitor (cat. no. L1033000; Becton Dickinson, Franklin Lakes, NJ). After sampling, blood was immediately placed on ice, and within an hour centrifuged at $915 \times \mathrm{g}$ for $15 \mathrm{~min}$ at $4^{\circ} \mathrm{C}$ for plasma collection. Plasma was frozen at $-20^{\circ} \mathrm{C}$. For experiments 1 and 2, plasma was analyzed for glucose (glucose oxidase/peroxidase method, modified from Karkalas, 1985), NEFA (NEFA-C kit; Wako Fine Chemical Industries USA, Dallas, TX; Johnson and Peters, 1993), and BHBA (Gibbard and Watkins, 1968).

Puncture biopsy was performed under local anesthesia (10 mL of lidocaine). Liver samples were rinsed in saline, frozen in liquid nitrogen, and then stored at $-20^{\circ} \mathrm{C}$ until analysis of TAG concentration. Samples were thawed on ice, blotted dry, and approximately 0.1 $\mathrm{g}$ of tissue was homogenized in $3 \mathrm{~mL}$ of saline using an ultra-Turrax T25 homogenizer (Rose Scientific Ltd., Edmonton, AB, Canada). An aliquot was used for total lipid extraction by the method of Folch et al. (1957). Concentration of TAG was determined using a colorimetric assay (Foster and Dunn, 1973). A second aliquot of the homogenate was used to measure DNA content of the sample (Labarca and Paigen, 1980).

\section{Statistical Analysis}

All data were covariately adjusted and analyzed with the MIXED procedure of SAS (SAS Institute, 2001). Before statistical analysis, data were confirmed to be normally distributed by visual data checking of the normal probability plot, the residuals by day plot and the residuals by predicted values plot. In addition, normality was assessed by Shapiro-Wilk, Kolmogorov-Smirnow, Cramer-Von Mises, and Anderson-Darling normality tests. Plasma metabolites for both experiments, and liver measurements for experiment 2 were statistically analyzed using repeated measurements in time (Littell et al., 1998). The covariance structure used to
Table 1. Effect of rumen-protected choline (RPC) on plasma metabolites during feed restriction (experiment 1$)^{1}$

\begin{tabular}{lcccc}
\hline Metabolite & Control & RPC & SEM & $P$-value \\
\hline Plasma glucose, mg/dL & 48.3 & 51.4 & 1.5 & 0.14 \\
Plasma NEFA, $\mu E q / L$ & 703 & 562 & 40 & 0.004 \\
Plasma BHBA, mg/dL & 7.6 & 8.0 & 0.4 & 0.47 \\
\hline
\end{tabular}

${ }^{1}$ Covariately adjusted least squares means.

best fit the model was selected based on the lowest value given by the Akaike's information criterion.

For experiment 1, the statistical model included the effects of group and treatment. For experiment 2, the statistical model included the effects of group, treatment, day, hour nested in day, and the interaction between treatment and day. Results for plasma metabolites are reported as main effects because no significant interactions were found between sampling time and treatment.

Cow was the experimental unit and a random variable. Statistical significance of main effects was set at $P \leq 0.05$, and tendencies were declared at $P \leq 0.15$. Cows were paired by BW and BCS. However, the pair effect was not included in the final model because its lack of significance and the substantial reduction in degrees of freedom.

\section{RESULTS AND DISCUSSION}

\section{Experiment 1}

During the pretreatment phase, from d 0 to 6 , DMI was similar for the control and RPC groups $(18.5 \mathrm{~kg} / \mathrm{d}$, $\mathrm{SE}=0.78)$. During the feed restriction period, cows were limited to $30 \%$ of their energy requirements for maintenance and pregnancy; therefore, there were no refusals and DMI was found to be similar between treatments $(2.7 \mathrm{~kg} / \mathrm{d}, \mathrm{SE}=0.06)$.

A decrease in plasma NEFA concentration $(P<0.05)$ was observed when cows were supplemented with RPC (Table 1). Similarly, previous studies reported that supplementation with RPC starting at either 28 or $21 \mathrm{~d}$ before expected calving decreased plasma NEFA concentration (Oelrichs et al., 2004; Chung et al., 2005). However, in both studies, greater DMI and energy intake for the RPC-fed cows may have accounted for the results. Pinotti et al. (2003) observed a decrease in NEFA concentration at parturition when RPC supplementation started $14 \mathrm{~d}$ before expected calving, but no differences in DMI were observed. Conversely, other studies (Hartwell et al., 2000; Piepenbrink and Overton, 2002; Janovick et al., 2006) failed to find any effect of RPC supplementation on plasma NEFA concentration. The reduction in plasma NEFA observed 


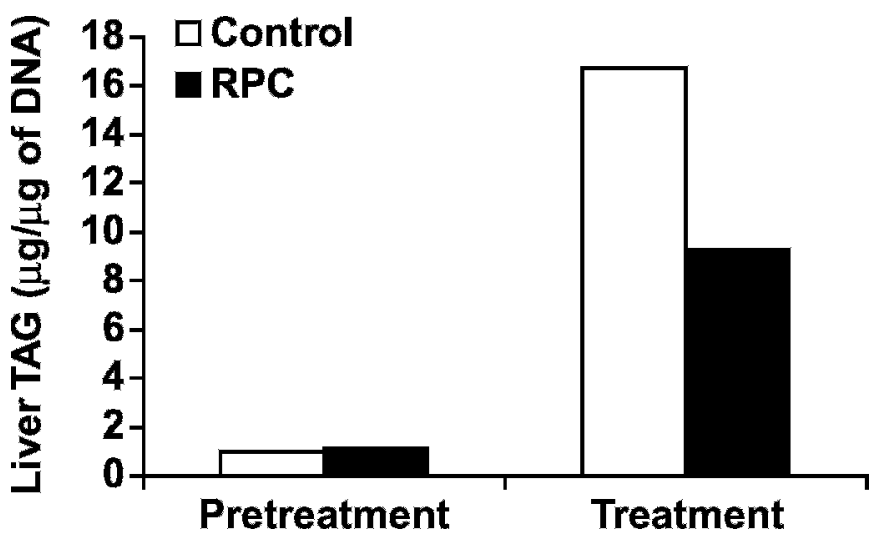

Figure 1. Liver triacylglycerol concentrations (TAG) for experiment 1 before treatment application on d 0 (pretreatment) and after the cows were feed restricted and supplemented with either 0 or 15 $\mathrm{g}$ of choline as rumen-protected choline (RPC)/d for $10 \mathrm{~d}$ (treatment). Liver TAG values following treatment are covariately adjusted least squares means. Cows fed RPC had lower liver TAG $(P=0.02 ; \mathrm{SE}=2.0)$.

when RPC was supplemented may indicate an effect of choline on adipose tissue mobilization, NEFA clearance from blood, or both.

Rumen-protected choline administration had no effect on plasma BHBA concentration (Table 1), suggesting that RPC did not affect hepatic ketogenesis, despite the difference in plasma NEFA concentration. Likewise, previous studies (Hartwell et al., 2000; Piepenbrink and Overton, 2002; Janovick et al., 2006) reported no effect of RPC on plasma BHBA, even when NEFA was reduced by RPC at calving (Pinotti et al., 2003). In contrast, Oelrichs et al. (2004) found a decrease in the BHBA plasma concentration in conjunction with an increase in DMI and decrease in plasma NEFA concentration.

Liver TAG accumulation during negative energy balance was reduced by $\operatorname{RPC}(P<0.05$; Figure 1$)$ and directly associated with plasma NEFA concentration. Elek et al. (2004) reported that cows fed RPC had a decrease in liver TAG accumulation after calving, whereas studies from Hartwell et al. (2000) and Piepenbrink and Overton (2002) found no effect of RPC on liver TAG. The mechanism by which RPC reduces liver TAG in dairy cows is unknown. Previous studies with laboratory animals (Yao and Vance, 1990) demonstrated that choline deficiency limited PC synthesis, caused a reduction of lipid (mainly TAG) content in hepatic VLDL, decreased VLDL secretion from liver, and led to fatty liver development. However, because NEFA uptake by the liver is a function of blood flow to the liver and NEFA concentration in blood, it is possible that some or all of the reduction in liver TAG observed in this experiment may have been due to an indirect effect of choline reducing plasma NEFA instead of a direct effect of enhancing TAG export from the liver. In addition, other potential effects of choline on liver TAG accumulation could be related to FA oxidation by means of increasing carnitine levels. Betaine, the product of the irreversible oxidation of choline in liver and kidney, plays an important role as a methyl donor. In guinea pigs and humans, feeding betaine resulted in greater conservation of carnitine in skeletal muscle (Daily and Sachan, 1995; Dodson and Sachan, 1996). Addition of carnitine to culture media of liver slices was found to increase palmitate oxidation (Drackley et al., 1991). Therefore, it could be speculated that supplementing RPC may increase carnitine accretion and fatty acid oxidation, leading to a decrease in NEFA concentrations. However, Piepenbrink and Overton (2002) failed to find an effect of feeding RPC on the capacity of liver slices to oxidize palmitate. Therefore, supplementation with RPC may reduce TAG accumulation in liver by either or all mechanisms; decreasing NEFA plasma concentration, supplying PC for VLDL synthesis, and increasing fatty acid oxidation in liver.

Plasma glucose concentration tended to be greater for RPC-fed cows (Table 1; $P=0.14$ ), and because feed intake was restricted and similar between treatments during the sampling period, these differences in plasma glucose were independent of energy intake. The decreased plasma glucose concentration observed for the control group may indicate an impaired hepatic gluconeogenesis or an increase in glucose uptake by peripheral tissues. Hartwell et al. (2001) did not find any significant effects of supplemental RPC on mRNA expression for some enzymes regulating gluconeogenesis; however, in that study, RPC had no effect on liver TAG accumulation. Hepatic TAG accumulation has been found to impair hepatic gluconeogenesis in vitro (Strang et al., 1998a). So, differences in liver TAG accumulation between treatments may explain the observed trend in plasma glucose.

\section{Experiment 2}

Dry matter intake was not affected by treatment during feed restriction from d 0 to $10(2.6 \mathrm{~kg} / \mathrm{d}, \mathrm{SE}=0.09)$ or during ad libitum feeding from d 11 to $16(13.3 \mathrm{~kg} /$ $\mathrm{d}, \mathrm{SE}=0.49$ ). Because DMI did not differ between treatments, differences in plasma metabolites and liver TAG can be attributed to the presence or absence of RPC in the diet. Studies from Hartwell et al. (2000) and Piepenbrink and Overton (2002) also reported no differences for DMI by cows fed RPC when compared with controls, but Oelrichs et al. (2004) and Chung et al. (2005) reported that cows fed RPC had significantly greater DMI. 


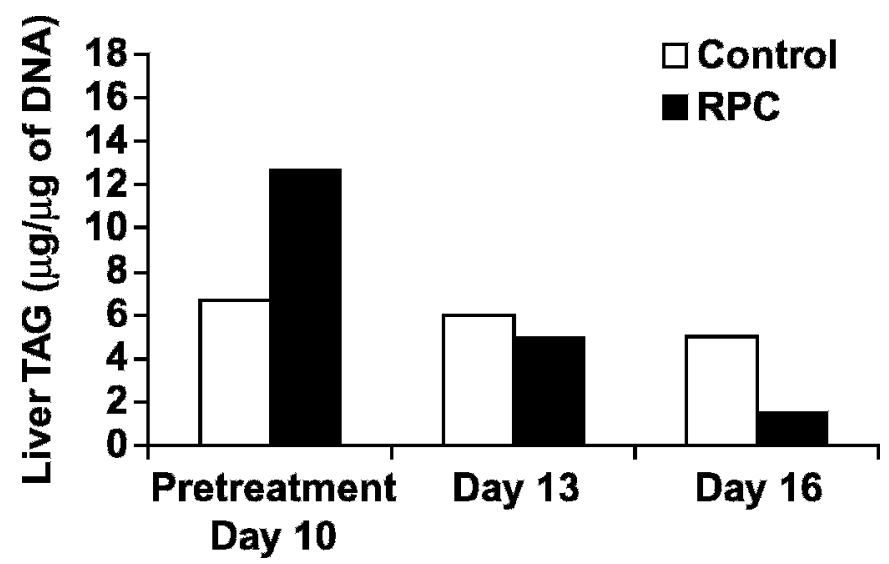

Figure 2. Liver triacylglycerol concentrations (TAG) for experiment 2 , at $10 \mathrm{~d}$ after the initiation of the feed restriction protocol and before treatment application (pretreatment), and at 13 and 16 $\mathrm{d}$ when cows were allowed to consume feed ad libitum and supplemented with 0 or $15 \mathrm{~g}$ of choline as rumen-protected choline (RPC)/ $\mathrm{d}$ for 3 and $6 \mathrm{~d}$, respectively. Liver TAG values following treatment, at $\mathrm{d} 13$ and 16, are covariately adjusted least squares means. Feeding RPC increased depletion of TAG from liver $(P=0.02 ; \mathrm{SE}=0.4$ for $\mathrm{d}$ 13 and 0.9 for $\mathrm{d} 16)$. Treatment by time interaction was significant $(P=0.05)$.

There were no treatment effects on plasma glucose $(60.4 \mathrm{mg} / \mathrm{dL}, \mathrm{SE}=0.9)$, BHBA $(6.3 \mathrm{mg} / \mathrm{dL}, \mathrm{SE}=0.4)$, and NEFA concentrations $(124 \mu \mathrm{Eq} / \mathrm{L}, \mathrm{SE}=6.0)$. Liver TAG values for cows destined to receive control or RPC treatments at the end of the feed restriction period (pretreatment) were 6.7 and $12.7 \mu \mathrm{g} / \mu \mathrm{g}$ of DNA, respectively. This was unexpected because no treatments were applied to animals during the feed restriction phase and animals were randomly assigned to treatments. Pretreatment liver TAG concentration was a significant covariate $(P<0.01)$; consequently, liver measurements obtained on $\mathrm{d} 13$ and 16 (d 3 and 6 following initiation of ad libitum feeding) are expressed as covariately adjusted means. There was a significant treatment effect on liver TAG $(P=0.02$; Figure 2$)$, with RPC increasing the clearance of liver TAG during positive energy balance.

The mechanism by which RPC supplementation enhances liver TAG depletion cannot be elucidated from this study. However, enhanced VLDL export and hepatic FA oxidation are possibilities, particularly because there were no treatment differences on plasma NEFA, BHBA, or DMI. In nonruminants, the synthesis of $\mathrm{PC}$, a choline-derived phospholipid, has been found to be necessary for the assembly and secretion of VLDL (Yao and Vance, 1988), suggesting a role of choline in hepatic TAG exportation. However, results from experiment 2 must be interpreted with caution because of the discrepancy in liver TAG between the groups before the beginning of treatments.
The model used in both experiments was designed to examine if RPC supplementation could prevent or alleviate fatty liver in far-off dry cows experiencing or recovering from periods of elevated plasma NEFA resulting from feed restriction (Bertics and Grummer, 1999). The depression in energy intake at calving is usually not as drastic as that used in this model (Hayirli et al., 2003). However, our objective was to have a sufficient fatty acid mobilization to increase liver TAG within the range observed for transition cows. Because far-off dry cows do not experience endocrine changes associated with parturition that stimulate fatty acid mobilization, we elected to exaggerate the drop in energy intake to induce a similar extent of liver TAG accumulation to that observed at calving. By using faroff dry cows restricted to a common energy intake, we expected less variation in liver TAG compared with transition cows. Unfortunately, the model did not completely eliminate this problem, as seen in experiment 2 , in which variation in liver TAG was high before the beginning of treatments. Caution must be applied when extrapolating these results to periparturient cows because DMI was restricted beyond that observed at peripartum, and endocrine changes associated with parturition were missing from the model.

\section{CONCLUSIONS}

Two experiments were designed to examine if RPC could prevent or alleviate fatty liver caused by feed intake restriction of far-off dry cows. In both experiments, RPC was found to have a positive effect on reducing hepatic TAG. The mechanism by which RPC affects hepatic TAG concentration was not elucidated in these studies, but it may involve increased fatty acid oxidation or TAG export from the liver.

\section{ACKNOWLEDGMENT}

The authors thank Balchem Encapsulates for the financial support of this research.

\section{REFERENCES}

AOAC. 2006. Official Methods of Analysis. 18th ed. Association of Official Analytical Chemists International, Washington, DC. http://eoma.aoac.org/ Accessed Oct. 11, 2006.

Atkins, K. B., R. A. Erdman, and J. H. Vandersall. 1988. Dietary choline effects of milk yield and duodenal choline flow in dairy cattle. J. Dairy Sci. 71:109-116.

Bell, A. W. 1980. Lipid metabolism in the liver and selected tissues and in the whole body of ruminant animals. Pages 636-410 in Lipid Metabolism in Ruminant Animals. W. W. Christie, ed. Pergamon Press, Oxford, UK.

Bertics, S. J., and R. R. Grummer. 1999. Effects of fat and methionine hydroxy analog on prevention or alleviation of fatty liver induced by feed restriction. J. Dairy Sci. 82:2731-2736. 
Chung, Y. H., T. W. Cassidy, I. D. Girard, P. Cavassini, and G. A. Varga. 2005. Effects of rumen protected choline and dry propylene glycol on feed intake and blood metabolites of Holstein dairy cows. J. Dairy Sci. 88(Suppl. 1):61. (Abstr.)

Daily, J. W., and D. S. Sachan. 1995. Choline supplementation alters carnitine homeostasis in humans and guinea pigs. J. Nutr. 125:1938-1944.

Dodson, W. L., and D. S. Sachan. 1996. Choline supplementation reduces urinary carnitine excretion in humans. Am. J. Clin. Nutr. 63:904-910.

Drackley, J. K., D. C. Beitz, and J. W. Young. 1991. Regulation of in vitro palmitate oxidation in liver from dairy cows during early lactation. J. Dairy Sci. 74:1884-1892.

Elek, P., F. Husveth, T. Gaal, and J. R. Newbold. 2004. Effect of rumen protected choline on liver metabolism in periparturient dairy cows. J. Dairy Sci. 87(Suppl. 1):343. (Abstr.)

Erdman, R. A. 1992.Vitamins. Pages 297-308 in Large Dairy Herd Management. H. H. VanHorn and C. J. Wilcox, ed. American Dairy Science Association, Savoy, IL.

Folch, J., M. Lees, and G. H. Sloane Stanley. 1957. A simple method for the isolation and purification of total lipids from animal tissues. J. Biol. Chem. 19:338-340.

Foster, L. B., and R. T. Dunn. 1973. Stable reagents for determination of serum triglycerides by a colorimetric Hantzsch condensation method. Clin. Chem. 19:338-340.

Gibbard, S., and P. J. Watkins. 1968. A micro-method for the enzymatic determination of $\mathrm{D}$ - $\beta$-hydroxybutyrate and acetoacetate. Clin. Chim. Acta 19:511-521.

Griffith, W. H. 1941. The effect of supplementary choline, methionine and cystine and of casein, lactoalbumin, fibrin, edestin and gelatin in the hemorrhagic degeneration in young rats. J. Nutr. 21:291-305.

Grummer, R. R. 1995. Impact of changes in organic nutrient metabolism on feeding the transition dairy cow. J. Anim. Sci. 73:2820-2833.

Hartwell, J. R., M. J. Cecava, and S. S. Donkin. 2000. Impact of dietary rumen undegradable protein and rumen-protected choline on intake, peripartum liver triacylglycerol, plasma metabolites and milk production in transition dairy cows. J. Dairy Sci. 83:2907-2917.

Hartwell, J. R., M. J. Cecava, and S. S. Donkin. 2001. Impact of rumen undegradable protein and rumen-protected choline on mRNA expression for enzymes in gluconeogenesis and ureagenesis in liver of periparturient dairy cows. J. Dairy Sci. 84:490-497.

Hayirli, A., R. R. Grummer, E. V. Nordheim, and P. M. Crump. 2003. Models for predicting dry matter intake of Holsteins during the prefresh transition period. J. Dairy Sci. 86:1771-1779.

Janovick, N. A., D. B. Carlson, J. E. Garrett, and J. K. Drackley. 2006. Lipid metabolite profile and milk production for Holstein and Jersey cows fed rumen-protected choline during the peripartum period. J. Dairy Sci. 89:188-200.

Johnson, M. M., and J. P. Peters. 1993. An improved method to quantify nonesterified fatty acids in bovine plasma. J. Anim. Sci. 71:753-756.

Jorritsma, R., H. Jorritsma, Y. H. Schukken, and G. H. Wentink. 2000. Relationships between fatty liver and fertility and some periparturient diseases in commercial Dutch dairy herds. Theriogenology 54:1065-1074.
Karkalas, J. 1985. An improved enzymatic method for the determination of native and modified starch. J. Sci. Food Agric. 36:10191027.

Kleppe, B. B., R. J. Aiello, R. R. Grummer, and L. E. Armentano. 1988. Triglyceride accumulation and very low density lipoprotein secretion by rat and goat hepatocytes in vitro. J. Dairy Sci. $71: 1813-1822$.

Labarca, C., and K. Paigen. 1980. A simple, rapid, and sensitive DNA assay procedure. Anal. Biochem. 102:344-352.

Littell, R. C., P. R. Henry, and C. B. Ammerman. 1998. Statistical analysis of repeated measures data using SAS procedures. J. Anim. Sci. 76:1216-1231.

Lundberg, K. L., P. C. Hoffman, L. M. Bauman, and P. Berzaghi. 2004. Prediction of forage energy content by near infrared spectroscopy and summative equations. Prof. Anim. Sci. 20:262-269.

Mertens, D. R. 1999. Variation in aNDF results with modifications of the filter bag method. National Forage Testing Association, Technical Session Papers and Committee Reports to the Board and Membership, Topeka, KS.

National Research Council. 2001. Nutrient Requirements of Dairy Cattle. Natl. Acad. Sci., Washington, DC.

Oelrichs, W. A., M. C. Lucy, M. S. Kerley, and J. N. Spain. 2004. Feeding soybeans and rumen-protected choline to dairy cows during the periparturient period and early lactation. Effects on production and energy balance. J. Dairy Sci. 87(Suppl. 1):344 (Abstr.)

Piepenbrink, M. S., and T. R. Overton. 2002. Liver metabolism and production of cows fed increasing amounts of rumen-protected choline during the periparturient period. J. Dairy Sci. 86:17221733.

Pinotti, L., A. Baldi, I. Politis, R. Rbucci, L. Sangalli, and V. Dell'Orto. 2003. Rumen-protected choline administration to transition cows: Effects on milk production and vitamin E status. J. Vet. Med. A Physiol. Pathol. Clin. Med. 50:18-21.

SAS Institute. 2001. SAS User's Guide: Statistics. Version 8 ed. SAS Institute, Inc., Cary, NC.

Sharma, B. K., and R. A. Erdman. 1989. In vitro degradation of choline from selected feedstuffs and choline supplements. J. Dairy Sci. 72:2772-2776.

Strang, B. D., S. J. Bertics, R. R. Grummer, and L. E. Armentano. 1998a. Effect of long-chain fatty acids on triglyceride accumulation, gluconeogenesis, and ureagenesis in bovine hepatocytes. J. Dairy Sci. 81:728-739.

Strang, B. D., S. J. Bertics, R. R. Grummer, and L. E. Armentano. 1998b. Relationship of triglyceride accumulation to insulin clearance and hormonal responsiveness in bovine hepatocytes. J. Dairy Sci. 81:740-747.

Wildman, E. E., G. M. Jones, P. E. Wagner, R. L. Boman, H. F. Troutt, and T. N. Lesch. 1982. A dairy cow body condition scoring system and its relationship to selected production characteristics. J. Dairy Sci. 65:495-501.

Yao, Z. M., and D. E. Vance. 1988. The active synthesis of phosphatidylcholine is required for very low density lipoprotein secretion from rat hepatocytes. J. Biol. Chem. 263:2998-3004.

Yao, Z. M., and D. E. Vance. 1990. Reduction in VLDL, but not HDL, in plasma of rats deficient in choline. Biochem. Cell Biol. 68:552-558. 